\title{
16. Change and Continuity in Anthropology: Examples from Christianity and from the situations of contemporary Indigenous Australians
}

\author{
Francesca Merlan
}

\section{Anthropology and change}

My chapter focuses on change in anthropology, with some comparative references to other social sciences. I illustrate what I have to say through two particular areas of ethnographic research and theorisation - the anthropology of Christianity, and of the contemporary situations of indigenous peoples, particularly in Australia. My treatment is focused, rather than comprehensive; I make no claims to completeness. My view is that, despite its importance, change remains relatively under-conceptualised in these areas, and one of my aims is to encourage greater adequacy among all of us practitioners.

We may define change as difference in some field, object or relation over time. That brief, rough and ready definition raises plenty of issues of importance in the social sciences, which is after all about social life and its self-aware and otheraware players, familiar in some version to all of us. Among other questions, how and when do we discern change? Whose discernment of change is at issue? What are seen to be its consequences? Along what dimensions do we notice and conceptualise change?

To position anthropology in relation to change, I am going to begin by claiming there is a kind of schizophrenia in the social sciences. We talk about some phenomena as if they are inevitably associated with great and irreversible change (e.g. economic modernisation, industrialisation, many new technologies, or colonialism). These are areas of 'change-assertiveness'. It is taken almost for granted that their occurrence or operation involves change, often great change, but it always turns out to be complicated to specify what that change amounts to, and how to specify the sorts of processes, relations and dimensions involved. 
On the other hand, we talk about other phenomena, such as certain kinds of social relationships, with a great deal more 'change-reluctance'. Consider, for example, the issue of the relation of Indigenous people (for whom one of the accepted 'tribal' terms is Ngunuwal) to Canberra. If talked about in the framework of colonisation, we might think in terms of great change having occurred in Indigenous relationships to the place we now call Canberra, the created national capital, as the form of life of Indigenous people changed drastically. But now that some national land rights scaffolding exists for recognising relationships to places, and recognition is associated with particular social and political values, we are concerned to acknowledge this relationship as continuousthough we might admit some discontinuity in its having been unrecognised or ignored for some period of time. We background 'differences over time' for the Ngunuwal because - despite the obviousness of many questions the assertion may raise that the Ngunnawal people (alternatively called Ngunawal tribe by a competing group) are the Indigenous Australian inhabitants whose traditional lands encompass much of the area now occupied by the city of Canberra, Australia, and the surrounding Australian Capital Territory - we are concerned to assert, to 'socially construct' (Hacking 1999), as some would say, a relation of continuity between people and place. Perhaps it is very significant that some see this relationship as linked to our common present; it is less a remote historical process that we are talking about because of that. It is also one about which there are strong views and engagements, on the part of anthropologists and others.

It seems we can hardly get much further without mentioning the twin of change: continuity. We could define this as stability in some field, object or relation over time, which perhaps is very likely to have implications for the present. It is often observed that continuity should not be taken for granted: if things seem to remain the same over time, that also requires explanation. Again, there are questions of perspective: what do people themselves, in their various situations, make of change and/or continuity and its implications for them and their lives?

I hope that my examples, though spare, have been sufficient to show that, for both change and continuity, there are questions about modalities of sociohistorical change, people's discernment and experience of it as such, and their evaluation of it. I also have meant to intimate that both change and continuity involve expenditures of energy; both are actively produced in the human world, and discerned in particular circumstances. And especially the above example of continuity is such because it connects directly with the/our present. That also leaves it open to a politics of contemporary position-taking. There are those who would deny the relation of Ngunuwal to Canberra (including rival Indigenous 
groups), and in that process, would probably take a critical view of continuity of their relation to the area as 'constructed', perhaps even in the negative sense of fabricated.

I next want to locate anthropology historically, relative to its sister disciplines, as having been much more oriented to continuity than change. The most obvious comparison and contrast is with the closely allied social sciencesnotably sociology. Anthropology emerges in this context at the high end of a continuity-change spectrum in terms of what anthropologists often assert about their research subjects; but both disciplines, from their beginnings, have been mobilised by concerns about change.

Let us take this back to disciplinary emergences. It is a generalisation-but useful for present purposes - to say that sociology, from around the eighteenth or early nineteenth century, depending on how you trace it, emerged as a recognisable discipline gaining some of its energies from anxieties about the force and inexorability of change in so-called modern or developed societies. Many of its theorists (Comte, Saint-Simon, much more recently Tarde, Durkheim, and many others) were also practitioners concerned with social planning, improvement and remedial activity to mitigate the destructiveness of processes of change. Anthropology, on the other hand, from roughly the nineteenth century onwards, began to be visible as an emergent area of changereluctance, much more concerned with non-industrial or preindustrial societies, and many of its predecessor theorists and earlier and later practitioners (Morgan, Tylor, Leenhardt) with documentation, protection and preservation of native peoples who were undergoing colonisation and missionisation. Thus there has always existed in anthropology an anxiety about loss, alongside concerns for preservation; and a recognition of relatively great power differences between dominant social orders and those colonised or otherwise marginalised peoples with whom anthropologists have tended to do their research. (Present differences between sociology and anthropology can no longer be described in terms of concerns with 'modern' and 'pre-modern' societies, respectively, but I am talking about earlier disciplinary histories and the perspectives of their practitioners, as well as some measure of continuity.) The 'deep structure' and 'deep history' of anthropology become more intelligible when considered as a series of perspectives on social life which arose in a context of world expansion, and with its research concerns focused on peoples who were among the less powerful in those processes.

There are now often aspects of reparations politics - in the case of Indigenous peoples, for instance, land and native title or other similar claims - that ask of them to demonstrate their continuing attachment to lands and traditions as the requirement and justification of those claims. This supports and amplifies concerns for authenticity, traditionality and unchangingness of law and custom 
among those people which may constitute for them a source of pride, as well as a considerable problem to the extent that they no longer are as they were, and do not live up to such expectations. This demand comes from the wider political society (such as Australia), not explicitly from anthropologists; but it tends to coincide with and support certain kinds of continuity-oriented depictions and forms of theorisation (Austin-Broos 2011).

\section{Continuity thinking and the anthropology of Christianity}

A few years back anthropologist Joel Robbins (2007) argued that there had been a failure of an anthropology of Christianity to coalesce (as compared with anthropologies of Islam and Buddhism, for example, which he sees as having greater disciplinary coherence). In considering why that might be, he argued that what he called 'continuity thinking' is in the 'deep structure of anthropological theorizing'. He identified continuity thinking as consisting in tendencies for anthropologists to argue for social persistence (even if some change is admitted); that what people experience as new is perceived through the old or conventional and accommodated to it; and to see change as a kind of 'perpetual process' in time, rather than eventful and discontinuity-producing. Anthropologists give primacy to continuity, he argued.

This might be seen as a matter of degree, or variation, compared with related social sciences like sociology. Anthropology and sociology do share a good amount of DNA, but as I said above, sociology was, from its recognised inception, more about 'us' than 'them', and more impelled by questions and anxieties about change which was nevertheless widely (never universally) accepted and seen as ineluctable, rather than about conservation and anxieties about loss of a diversity of 'others'.

How does his claim about primacy of continuity thinking relate to Robbins' point about the lack of a coherent anthropology of Christianity? Anthropology is at variance with Christianity, he asserts. Christianity is a religion of radical change, both with respect to conversion and eschatology. Its underlying postulates concerning time and change are different from those of anthropology, which emerged in some opposition to Christianity and its practical arm, missionisation.

Robbins also argues that anthropologists have been more concerned with belief as a state of mind, and something that can be stated propositionally ('belief that'), rather than belief as an act ('belief in'), as reflected, for example, in someone's slaughtering a chicken or hanging a stone in the corner of their house. I think a sharp differentiation between these two is problematic, 
but there is something to a distinction between that which is more and less explicitly articulated. At any rate, Robbins argues that concern with belief as propositional is compatible with continuity thinking, in that belief is seen as something that endures, rather than as an act. ${ }^{1}$

A final facet to his argument has to do with anthropology as a social science of the Other, of difference. Robbins (2007, 16) quotes anthropologist Stephan Palmié $(1995,92)$ : 'Our public identity (as well as our careers) in no small measure hinges upon our ability to represent certain social realities as "authentically different" (and if possible, traditionally so).' In other words, there is an investment in otherness, on the part of anthropologists as well as in others' expectations of them and their subject matter. Anthropologists stereotypically work with people on Pacific Islands or the Amazon, not with Poles or high-energy particle physicists. (There is of course contemporary anthropological work with precisely such people, so I am citing stereotypes that have their roots in earlier and some continuing anthropological practice, not my view of anthropology's range of practice today.) Concern with otherness is linked to a fear of homogenisation and change which might level difference; hence tendencies in anthropology to represent difference as persisting. I think there is some truth to this. But as per my remarks above about the Ngunuwal, such concerns are not limited to anthropology or anthropologists. To an extent they are an expression of concerns widespread within our societies, which get projected upon certain kinds of people in particular, and made part of the weft of disciplinary developments that have a lot of common warp with others. Such concerns need to be subjects of constant critical awareness.

\section{Change and Indigenous Australians}

That brings me to a second class of examples. I can speak of this subject from personal experience and conviction, and also cite a number of other colleagues as examples.

Anthropological models of change with respect to Indigenous Australia have changed quite considerably over time, but - this is my plea - not as much as they need to. They continue, in many cases, to be loosely articulated as a matter of change in certain 'domains' of activity or description, such as 'kinship',

\footnotetext{
1 This raises a question about how Robbins would see the relation between Christianity as a religion of radical change, and what he claims to be a basic Western cultural emphasis on belief as propositional; but I leave that aside here as something he does not directly address in this material. I think the proposition that Christianity is a religion of radical change is also a large generalisation: one needs to specify where emphases on radical change may be, and their impacts on people being introduced to varieties of Christianity.
} 
or in sociohistorical accounts of the relations between Indigenous and nonIndigenous people and institutions. All these are important. But alongside these necessary accounts, in what kinds of critical terms may change be understood?

Certain influential early models argued that comprehensive trends of change were linked to seemingly small changes: Sharp (1952) presented a seemingly simple shift from stone axe to steel axe in Cape York as linked to and cascading into a whole series of changes, in overt behaviour, in technology and conductrelations of kinship and gender, trading partnerships, relations with whiteswhich effectively radically altered Cape York Indigenous societies over a short span of time. We might call this an instance of 'collapse' theory. Sharp's depiction has both something positive and something not so positive about it. Sharp saw beyond change as simply involving, for example, material repertoire, and proposed that the chain of connections and implications of stone to steel, of technology to social relations, was far-reaching. On the other hand, he had little to say about adaptations by which social relations and the cultural field were reshaped, and different forms of life continue, rather than simply imploding. Other models featured adaptive processes, new negotiations, and interrelations with settlers more fully. To what extent has ethnography and research developed into more adequate evaluation and theorisation of change?

\section{Indigenous Australia and wider societal politics of change}

When I first began research in the Northern Territory in 1976, I had come from some similarly remote-feeling Great Plains research venues in North America. I sort of expected Australian Aborigines would be in similar situations to American Indians in agency towns and outlying settlements, and in general I think I had correctly gauged that they were exposed to a considerable range of impacts and influences from Australian settler society. I did not have particular expectations about peoples being 'traditional', culturally pristine or integral. So I was not disappointed. I got to know people in a whole variety of living situations, characterised by greater or lesser degrees of regular contact with versions of Australian society - in towns, on pastoral stations, or further afield.

However, two or three years after I began research, things started to happen that made clear an era of land rights was in preparation, and its operation was going to bring with it a whole series of expectations about the completeness and traditionalism of Indigenous people's connections to country-a phenomenon to which I referred above. This was going to impose upon current research, and upon Indigenous people themselves to varying degrees, a concern about how to respond to emergent possibilities. Claimable country under the Land Rights Act 
was all Crown land, and Crown land tended to be remote and not to have been used for productive settler ventures. Hence in many cases Aboriginal people, as they moved closer in to settler centres over decades and especially with changes in wage structures which caused many pastoralists to toss them off the land, had also become distanced from some of what were notionally their traditional areas, and the fullness and fluency of their knowledge was sometimes less than expected under the Land Rights Act.

So I spent a good part of a book I wrote on this subject arguing that the law, though intended to be beneficial, acted as an anti-change machine (Merlan 1998). Its requirements made it very difficult for researchers to treat the situations of these Aboriginal people in historical and experiential terms, as well as in unvarnished terms of cultural difference and increasing influence of dominant societal practices and norms upon them. Rather, in terms of the emerging legal issues one was stuck with arguing about Indigenous connection to land as a matter of ontology - their very being as tied up with landedness. This is, one can see, a way of asserting and producing continuity. Such a view can lead to conclusions that Indigenous people disconnected from land no longer have the qualities and credentials that others expect. Many non-Indigenous detractors of land rights in the Northern Territory had long since come to the conclusionperhaps many did not need any real evidence about the condition of Indigenous people to do so - that they did not deserve anything at all, any more than any other Territorian battler who has had to work hard for his block, and does not get anything given to him. These kinds of arguments may sound familiar because they have been aired so often.

This is important because it is all about wider societal politics of change, which, as I have said, also becomes part of the subject matter of what anthropologists can and did say about change. My position, simply put, was to argue for the objective reality of considerable change, and the importance of theorising change, as well as describing and accounting for the different understandings people have of it: what people make of themselves, and their situation, and think about change, in their circumstances. Arguments about change needed to be placed in a framework of Indigenous-non-Indigenous relationship, and to eschew nostalgic or accusatory fixation with change in Indigenous social orders as 'loss' (while recognising that both non-Indigenous and Indigenous people may see it that way or, alternatively, may wish for transformation). The complications of describing and theorising change relationally must be recognised, particularly for people between whom and the mainstream there continue to be large gulfs of difference, including power differences of marginalisation and dispossession. I argued (Merlan 1998) for placing the relations of Indigenous and non-Indigenous people, and their consciousness of each other, front and centre in an 'intercultural' framework. I also consider it 
important to keep in mind the assertion by Robert Tonkinson, whose work is discussed below, that the aims, desires, forms of social action and imagination of many Indigenous people remain quite distinct from that which the Australian majority would conceive of, or wish (Tonkinson 2004, 184).

Let us now consider another anthropologist, Gaynor Macdonald, who has done research for many years with Wiradjuri people in western New South Wales (Macdonald 2004, 2008). Up north, and especially in the land rights context, expectations and stereotypes were held that Indigenous people ought not to change: they were supposed to be traditional, and much criticised if seen not to be so; and, correspondingly, the extent of change was either excoriated by some as disqualifying, or de-emphasised by others seeking to retain a favourable positioning for Aboriginal people, in which traditionality was in focus.

Gaynor encountered stereotypes in the academy and outside it that southern Aboriginal people do not have any culture left. Any differences between them and others were not seen as culturally of value, but as deficits. So Gaynor has spent years doing what she describes as 'reinscribing recognition of the distinctive cultural practices, characterising Aboriginal peoples' lives in southeast Australia'. ${ }^{2}$ In other words, she sees much Wiradjuri practice as cultural in being learned and transmitted and taken as normal in a given milieu, as against the contrasting encompassing environment, roughly, of mainstream rural white Australia. She challenges a long-held view that these differences simply reflect failed processes of incorporation of Wiradjuri into the Australian mainstream, and have no consistency and substance of their own. So, in a way, she has been trying to counter thinking that says that everything has changed, and changed for the worse, levelling any worthwhile difference. She cannot, however, be accused of Robbins' 'continuity thinking': she is too aware of sociohistorical change for that. So her position lies in detaching notions of culture and difference from evaluations of authenticity and traditionality, and in arguing that culture (or what we may call cultural, in order to avoid reification and holism) changes, as do the people in specific historical circumstances. In this I agree with her, but we would also agree, I think, that Australian cultural politics, especially those of legitimation and recognition, will not easily be shifted from focusing on authenticity and traditionality.

2 Gaynor Macdonald web address, University of Sydney, sydney.edu.au/arts/anthropology/staff/profiles/ macdonald.shtml. 


\section{Indigenous Australia: two versions of continuity thinking}

Now I want to briefly take the case of two anthropological colleagues who, I think, have a different approach to describing and theorising change, and have produced, in my estimation, versions of continuity thinking, combined later (in the second case) with a modified view of societal transformation. They have postulated ontological continuity of Indigenous people and culture as inhering in specific areas of practice and thought, and seen these as relatively impervious to outside influence (partly because some Aborigines explicitly struggle to keep them so). In creating these depictions they produce valuable accounts of aspects of Indigenous sociality and condition, but the emphasis on, or assumption of, fundamental centrality and continuity of certain kinds limits their attention to subjecthood, agency, and internal shifts within immediate Indigenous social domains as well as with institutions which intersect with family, community life, and many aspects of wider Australian life. When change becomes overwhelmingly obvious - as at least one of these anthropologists now concedes - what is happening is seen as being related to particular recent policy changes and management regimes. But were there not forms of change all along?

It is not fortuitous, I think, that both have done research in geographically fairly remote areas of Australia. This not only means that contacts with settler Australia were in fact later than elsewhere and typically involved selected groups of outsiders rather than major settlement; but even more importantly, that these anthropologists see questions of change and continuity through this lens of 'late contact', positing a protracted continuity of separate and distinctive 'Indigenous culture' into the present, or until recently. I would argue instead that the question of what even selective settler-Indigenous interaction produces, and how to theorise it, has long been an issue.

Robert Tonkinson (formerly at The Australian National University, and then at the University of Western Australia until his retirement) has done longterm research both in Vanuatu and with the Mardudjara of Australia's Western Desert. Though at times he has used comparison between them as an instrument of description and exploration, I will concentrate on what he has to say about the latter here. In a recent publication Tonkinson $(2012,20)$ said of his years of work:

Initially, my research attention was dominated by the many obvious continuities that linked living Mardu Aborigines, a Western Desert people, to their recent 'pre-European' existence, but over time my research trajectory has shifted inexorably to one that foregrounds transformations in the analysis of Western impacts. 
A first matter of importance is the link Tonkinson makes, implicitly and explicitly, between environment, remoteness and cultural conservatism. The Mardu lived in an arid and marginal environment. They might therefore be seen as 'late contacted' and/or shielded for a time, and able to return to the desert at times, but did this mitigate the consequences of their relations with outsiders? This short introduction exemplifies some of the aspects of Tonkinson's argument which foregrounds environment and location:

Shielded by their forbidding environment, the Mardu were left largely undisturbed until relatively recently. They were attracted from the desert to fringe settlements: mining camps, pastoral properties, small towns, and missions, initially for brief periods. However, inducements offered by Whites who desired their labor (and, in the case of women, sexual services), plus a growing taste for European foodstuffs and other commodities, drew them increasingly into the ambit of the newcomers. Inevitably, they eventually abandoned their Nomadic, hunter-gatherer adaptation for a sedentary life close to Whites. Migration began around the turn of the century and ended as recently as the 1960s. The Mardu remain today among the more tradition-oriented Aborigines in Australia. ${ }^{3}$

The Mardu lived in places that were remote from intensive or large-scale settlement, but were contacted by colonists with a variety of interests. Not only did all sorts of settler enterprises and persons enter into the areas they regularly frequented, but one may not underestimate the significance of their responses. They did not stay put: they walked to places of interest to them, and into contact with whites, and there began the usual, unequal and often exploitative forms of labour, sexual and other relations. The community of Jigalong arose as a rations depot from the 1930s and later served as a maintenance station along the rabbitproof fence. Missionisation of the Mardu began after World War II. Tonkinson's view is that the disciplinary nature of the mission regime was undoubtedly oppressive with its dormitories, segregation of children, and so on. However, he also sees this as having put a barrier between Indigenous people and their would-be saviours, in a way that contributed to separation, with the Mardu remaining among the 'more tradition-oriented'. We begin to sense the need to closely examine the variety of relations with outsiders, and also resulting internal shifts in Mardu social relations, rather than simply an emphasis upon the maintenance of distance between themselves and whites. The various pieces of the puzzle do not seem to add up to a view of Mardu as culturally unaffected;

3 Read more: www.everyculture.com/Oceania/Mardudjara-History-and-Cultural-Relations.html\#ixzz2K5jIgCE3. 
they obviously had many kinds of relations with various sorts of outsiders, while observably maintaining certain practices (ceremony among others) more strenuously than Aborigines in many other locales.

In everything he has written Tonkinson has, rightly, been concerned to present Mardu as agentive, not mere passive subjects of colonising forces. But internal to this is a kind of emphasis upon continuity. He writes of their agency as having been predominantly directed towards protecting and maintaining Mardu cultural integrity. Everything else that has happened therefore appears as something aberrant, e.g.:

For the Mardu, access to alcohol and increasing Westernization pressures have led to considerable social problems, which remain unresolved. A recent movement to establish permanent outstations on or near traditional Mardu lands is partly in response to these pressures, particularly the damaging effects of alcohol, but it also relates to the advent of large-scale mining exploration in the desert. The Mardu strongly oppose these activities, and since the formation of a regional land council in the mid-1980s, a major concern has been to protect their lands from desecration and alienation. ${ }^{4}$

In explaining how the Mardu have oriented themselves towards cultural integrity, and also seeing the explanation of cultural persistence among the Mardu as a 'challenge' (Tonkinson 2004, 184) given the 'constancy of change', Tonkinson places considerable importance upon ritual and a presumably associated ideology. Drawing upon some major anthropological epitomes of Aboriginal life and culture (e.g. the work of WEH Stanner), as well as his own experience, he writes of Indigenous 'assent to the terms of life', a kind of quiescence or stoicism; and permanence and fundamental abidingness as permeating their feelings for the country (forms made by Dreamings, remaining for all time), the combination of which discourages questioning, scepticism and self-reflection. Myth, too, is seen as a medium of absorption of what may in some respects be seen as contemporary or new information and understanding into a framework of stable, if not static, understandings. While individuals receive new information via dreams and revelations (Tonkinson 1970) this, too, is seen as largely incorporated into ongoing frames. Ideology and ritual are seen as stabilising domains of life activity, reproducing and sizing contemporary life in familiar frames.

Now this is a fairly common and established picture of Indigenous ideology. It results, for Tonkinson as for some others, in a dichotomous framework of 'two worlds', or two 'domains', Aboriginal and non-Aboriginal, or ngurra 'camp'

4 Readmore:www.everyculture.com/Oceania/Mardudjara-History-and-Cultural-Relations.html\#ixzz2K5n6kHSo. 
and maya 'house', as the Mardu themselves often seem to epitomise this social difference. Aborigines are represented as having actively striven to keep these separate, and particularly in Tonkinson's earlier work (1974), this sometimes was seen as triumphal 'resistance' to the missionaries and their impositions. In this way, a sense of them as culturally integral is presented despite difficulties for them in achieving this. Tonkinson presents the socioculturally most central, as well as most rigorously defended, of Indigenous domains as Law or the ceremonial life.

In recent work, as indicated in the 2012 quote above, the balance of emphases has changed. Tonkinson (2007) presents the Mardu as still concerned to sustain differences of importance to them, and values of kin, country and ceremony as still core to sense of themselves and their way of life, but deliberate separation as no longer a successful strategy. Among other things, 'self-determination' policy and its successors have increasingly focused on making Mardu more directly involved in the administration and management of their communities, thus handing them responsibility for a different kind of 'business' than their Law, and in the process, blurring distinctions between Aboriginal and whitefella domains. He sees Mardu as having been reluctant to deploy their own organisational and logistic skills to management of community affairs $(2007,47)$; and practice of ceremony is weakened by numerous changes, including access to alcohol and drugs. Another feature of the present is heightened and more pressured mobility (to accomplish life tasks, for example - medical visits, bureaucratic paperwork), and a wider choice of residential locations (not only in remote communities, but in towns) - both realisations of valued autonomy, Tonkinson argues, but - one might also suppose - of social and cultural diversification and reorientation.

There seems little doubt that, in regions like this, remoteness from majority Australian society was relevant in many ways; and that ceremony and Law were highly valued Aboriginal activities, and areas of practice and imagination. But a problem with the presentation of 'domaining' and a core way of life so assertively, is that many things that are actually happening at any given time fall outside this frame, and thus appear as Aborigines failing to live in their own valued terms. These may be terms that Aborigines themselves articulate less clearly than ideal norms, or not at all. But they require some kind of theorisation that does not posit entire areas of activity (including Law) as necessarily or only conservative, but takes even those valued areas as possible arenas of change, or linked to changes in people's experience, sense of themselves, relationship to country, and to other people.

To wind back historically: how to treat Mardu going into places of European occupation, and rapid integration of Mardu into some forms of relationship with outsiders, in terms of its consequences for social relations among themselves and with others? Many explicit forms of Mardu self-presentation 
and self-understanding do, indeed, emphasise continuity over change (in the words of Indigenous people all over the country, and Mardu too, 'your laws change all the time, our Law never changes'). But at the same time an enormous number of things about Indigenous life and its relation to new people and elements are changing apace, perhaps unremarked or unarticulated, though certainly constituting some good proportion of the everyday. Not without conflict, of course; and not without inequality and the recognition of inequality.

However, Tonkinson says himself that his early work was 'dominated by the many obvious continuities that linked living Mardu Aborigines, a Western Desert people, to their recent "pre-European" existence'. This kind of representation generated a picture of normative Aboriginal subjectivity as continuity-oriented, to kin, place, ceremony. Obviously some parts of that depiction are consonant with Indigenous social practice and ideology; yet, clearly also, many aspects of change - differences in fields, objects and relations - were already afoot; for one, the basic shift from a self-subsistent life to a much more materially dependent one. What were the forms of Mardu self- and other-understanding in and of these situations? What were the patterns of internal relations, activities and movements, in undoubtedly growing awareness of the presence of outsiders? Was the Law always simply a domain of separation between Mardu and whites, or were there possibly changes in Mardu thinking and experience, that also made their way into the practice of Law, however separate it may seem? Do people sometimes continue to do some of the 'same' things, but re-position and relativise them in new ways? For example, when Mardu are exposed to teachings about God and Church but also continue to go to ceremony, do they simply shut those teachings out? Or do they, as others have reportedly done, also make overt amendments to their forms of ceremonial practice, as reported for missionised people further north in the Pilbara (Petri and Petri-Odermann 1970)? How tenable is it to identify particular domains of practice-like Law, or ceremony - as unchanging core to a form of life, and as impervious to outside influence? And to think of changes in social life in terms of such 'domains' of activity, instead of conceptualising some of the modalities of change in more fluid and distributed ways?

I think another example is useful to make more explicit one of the points inherent in the above discussion: that how and whether anthropologists characterise change, and continuity, is influenced by the main focus of their research. In the two cases I am considering these research areas turn out to be precisely those in which the strongest claims for continuity are made. 
Howard Morphy has worked with Indigenous 'art' and artists in the Northern Territory since the 1970s, and is an authority on the art and aesthetics of Yolngu people of north-east Arnhem Land. Over the years he has also been involved, together with his wife Frances who did linguistic work on one of the Yolngu dialects, in museology, film, multimedia, as well as native title work.

One of the summary points he and Frances Morphy assert on this research basis is that the Yolngu are encapsulated but not colonised. What should we take this to mean exactly? Is it possible to be 'encapsulated' without consequence for experience, relationship and practice? Is the focus on Yolngu being (and feeling?) enclosed within another, foreign social order? Or having around them an enclosing capsule, which restricts access to them and by them? What does such a view say about the anthropologist's concept of Indigenous awareness? The word 'colonisation' clearly has a negative ring; but what if we were to ask more neutrally about the influences upon Yolngu, which they may incorporate into their lives, both wittingly (as in choosing, say, to watch television or videos, go to church, drink alcohol, go to or not go to school) and unintentionally (as when influences from such sources become part of their concerns and imaginative horizon)?

The Morphys argue that Yolngu retain what they have come to call 'relative autonomy' in two respects: first, with respect to Euro-Australian society; and second, in internal areas of Yolngu life, some of which have retained much more continuity than others (Morphy and Morphy 2013). For instance, patterns of residence and kinship relations have, they say, shown great continuity, while the hunter-gatherer subsistence economy has been transformed into a 'mixed' economy in which hunting and gathering is supplementary. This makes some kinds of (fairly conventional) divisions into 'domains' such as 'the kinship system', 'the system of technology and production' and 'the ideational system', and claims that there has been more change in some areas than others. There may be more change in some areas of activity and social relationship than others; but what would be adequate evidence for this, and what are adequate conceptual and methodological bases for such an argument? I submit that quarantining change in terms of social and technical divisions or domains is more difficult than labelling makes it seem; and that there need to be a variety of levels and resources for conceptualising change. Quarantining is difficult partly because people themselves are active across such notional domains, their experience and action not restricted to one. All notional domains could offer examples of such complexity, but let us take the example of one form of activity. 
Morphy sees Yolngu art production as having considerable continuity; or at least some of the content of what is depicted in Yolngu artworks is 'traditional', its matter the travels, locations and interactions of dreaming figures within landscape, and content still largely tied to Indigenous notions of consubstantiality among people, places and dreamings.

However, the very category of 'art', I have previously argued (Merlan 2001), has involved considerable change in some ways, as do the materials and the conditions of wider display of the works. Designs and stories such as these were not, as is also true of central Australia and elsewhere, displayed to an outside public. They are now produced in a quite different time frame and for different audiences, including markets, than was previously the case. Here as elsewhere this has occasioned some internal debate about what may be represented and what not. This indicates that people certainly do recognise identity in what is being shown, and continuities in who may paint which designs, but sometimes differ over how these things are to be transferred into a very different environment, and who has authority over the production of designs, among other matters. Morphy (1991) has argued for various kinds of change in Yolngu painting, so the question is not whether anything has changed, but what has changed, how the people involved see this, and how they articulate ways of understanding change and continuity in their current situation.

Distinguishing between paintings that are mainly geometric, and others that are mainly figurative, Morphy (1991) shows that the former encode the most highly restricted ('inside') and valued meanings and relationships in ways that the latter, relatively more 'outside' figurative paintings and motifs cannot; and that European interest in Yolngu painting has been accompanied by changes in production and the ways and venues in which painting currently figures. Women also have greater access to inside meanings than before. Yet overall, Morphy's argument is that Yolngu painting remains a fundamental underpinning and medium of Yolngu society and knowledge, with change in the forms of knowledge and understanding considered only rather peripherally.

One thing I think Yolngu have managed with success is transfer of some of what they themselves think of as high cultural production-dancing, painting, song and so on-into a number of new, highly constructed environments (involving non-Indigenous partners and collaborators) which are framed in a way that brings respect and admiration for their accomplishments from a wider Australian public. One of the best-known and most innovative offerings has 
been the music of Yothu Yindi, a group with both Aboriginal and baland ${ }^{5}$ (non-Aboriginal) members formed in 1986, and combining Aboriginal music with rock and pop sound and instrumentation.

The emergence of the popular Garma festival - a now annual three-day event organised from Yirrkala which brings together ceremony (bunggul), song (manikay), art (miny'tji) and Yolngu dance for display to outside audiences and locals - is a great example, in a limited time frame and highly constructed environment, of another aspirational presentation of Yolngu culture which has met with great popular acclaim.

Especially if one's interests focus on the art industry and ceremonial practice (however innovatively modified to incorporate contemporary opportunities and constraints, as with Garma) the Yolngu world looks much more ordered than if you look at health (mental and physical), economic dependence, social tensions, alcohol and drug abuse, suicide rates, impoverished educational provision, literacy. Morphy's art study $(1991,304)$ indeed mentions alcohol issues only briefly, and in conclusion, in the time-honoured manner of anthropological ethnographic closing mentions of change. There is something to be said for different kinds and rates of change and continuity in different areas of social activity, which is one sense the Morphys want to give to 'relative autonomy'. But it is not clear how neatly many of these things can or should be separated from each other as 'domains', nor is it clear that one is justified in beginning in many of these areas from an assumption of autonomy, which in this case would presumably mean Yolngu organisation of activity and context, without (major) influence from others. It is, most of all, not clear how one may evaluate change which takes the kind of course I have described: a certain (increasing?) elaboration of high cultural production for shared (Indigenous and nonIndigenous) consumption, which people may be enormously proud of, and not readily describe in terms of change but assert as evidence of cultural continuity despite the obvious novelty of some fundamental aspects of these arrangements. Such a discussion needs a series of critical concepts which are not simply descriptive of kinds of activity, or meta-political notions (such as 'autonomy'). Ways of expressing directions and trends of change are important, as are description and interpretation of changing relationships and practices.

It is clear that Yolngu leadership is more articulate than in many other parts of Australia about a notion of biculturalism, and in assertions of the equivalence of Yolngu and Balanda cultures. In part, this needs to be understood in terms of the relatively benign history of missionisation, which was the principal form of colonisation of this area until relatively recently.

5 Balanda is the term used for 'whites' in north-east Arnhem Land, said to be derived from the word 'Hollander' (via Makasar Balanda, Malay Belanda, from Dutch Hollander). 
Morphy's view of Yolngu culture, and its vocabulary of 'relative autonomy', is in fact very like that of some articulate Yolngu: of a social order that retains its fundamental distinctive character and brings that to adaptive, creative interaction with outsiders, balancing 'white man's society and Yolngu society'. What presumptions concerning change and continuity underlie that?

I think it is all too easy to see (especially north-east Arnhem Land, and perhaps parts of Australia's deserts, as opposed to more densely and diversely colonised areas of Australia) through a lens of relatively late contact; and to minimise the consequences of mission-led education, occupational and domestic change efforts, as not full-fledged until the postwar 1950s. It certainly is appropriate to recognise great differences between settler and Yolngu social dynamics. But to simply take an integralist view screens us from grasping conditions that Yolngu inhabit today, as well as from adequately conceptualising previous Indigenousnon-Indigenous relations. Today's conditions manifest themselves in diverse ways: dramatically, for one thing, in the emergence of high suicide rates among those who live in, or shuttle between, outlying outstations and larger settlements like Yirrkala; more benignly, for another, in the manifest biculturalism of Yolngu rhetoric directed to an outside audience. Where in Australia is this to be found, and what social conditions have fostered it?

The overt and latent effects of long-term Methodist mission presence (established in 1935)-including transformation of residence patterns, daily routines, joint mission-Indigenous political and land rights activism which became famous throughout Australia in the matter of the Bark Petition of $1963^{6}$ - cannot be understood only in terms of Yolngu cultural integralism asserting itself in adaptive forms (see e.g. Baker 2010). In my view, understanding of the kinds of persons and orientations that resulted from the north-east Arnhem mission period and later events requires theorisation of Indigenous-non-Indigenous relations at many levels and across time. 'Relative autonomy', the label the Morphys apply to the Yolngu situation, defers conceptualisation of fundamental aspects of social process in favour of a culturally integralist 'minimum change' view. Importantly, it sidelines questions of shifts in connections between practice and how and what people think, and the growing sense of awareness of other ways of living in many respects. Yolngu are proud of the culture they are able to present yearly at the Garma festival. But what changes when culture is projected into these constructed environments, before outside audiences, as has long been the case with Indigenous 'art'? Assumptions are being made

\footnotetext{
6 A petition sent to Parliament in Canberra from north-east Arnhem Land in protest of the federal government's acquisition of an area as a mining lease, without consultation with people at Yirrkala. The petition is on permanent display in Parliament House in Canberra. Clearly missionaries and Yolngu collaborated in the production of this document, but celebratory acclaim tends to ignore, perhaps understandably, the participation of the former, and highlight the role of the latter.
} 
concerning continuity here, without that being adequately subjected to analysis of its organisation, the collaborations and intersections of ideas and interests. To even understand the rather considerable extent to which Yolngu are given to objectifying 'society' and 'culture', and the terms in which they do so, requires another view of sociohistorical process which the concept of 'relative autonomy' only glances off.

\section{Conclusions}

Some ways of positing research orientations in the social sciences, I said at the beginning, are 'change-accepting' - such is the vocabulary of urbanisation, sedentisation, and colonisation. Some are change-resistant, and I have concurred to an extent with Robbins' general view that anthropology has (often) been so (though I have not considered or accepted all of his generalisations about Christianity). But anthropology, as a social science that prides itself on 'going where the people are' (Hart 2002), ought, I think, once again not only to go there, but also to attempt renewal of its critical theorisation of processes of change and continuity. Such theorisation, I have argued from Australianist examples, cannot be well founded on structural notions of domains of social, economic or technical activity and relationship. Experiential and cognitive processes extend across all kinds of human activity. They require critical and conceptual vocabularies and forms of analysis which appear, still, to only be inchoate in all of the indigenist work I have presented here, including only partially developed in my own. In my view, anthropologists need to be clear that broad characterisations of people as 'tradition-oriented' or otherwise form part of an often emotively laden, public as well as sometimes indigenous, vocabulary of evaluation: what people make of themselves and others in circumstances as they apprehend them. We need to recognise these evaluations as one of the dimensions for critical analysis, rather than as an anthropological position-and focus instead on development of better frameworks for articulating how shifts in kinds of practice and kinds of people relate to each other.

I think that all of us whom I have discussed would be likely to agree that we have to pay attention to regional differences in how settler-Indigenous histories are to be described in different parts of Australia, and the different periodisation of colonisation and power-laden impacts upon Indigenous societies. I have suggested that studies of geographically remote Indigenous social settings are liable to simplify the social consequences of remoteness, seeing it as contributing to separation and cultural conservatism. But recognition of regional differences, however important, is not the main issue. More fundamentally, I think we differ in the ways in which we analyse those histories as involving differences in fields, objects and relations over time, i.e. in the ways we conceptualise 
change. We differ in conceptualising dynamics of Indigenous-non-Indigenous interaction, and the dispersed effects of social forces that are not directly visible, and are not articulated as such in people's ways of understanding themselves.

I have grouped Macdonald and myself together in that we seem to agree that Indigenous-non-Indigenous social and cultural differences persist in changing ways - and that these differences are cultural, that is learned and reproduced; but also, that even what seems (to subjects themselves) to be most fundamental to the way they are is open to history. In the case of long-term colonisation of the Wiradjuri, they have completely discontinued their practice of Law, but they continue to reproduce what they and others see and sense as distinctive familial relationships and social forms. The forms these practices take are certainly shaped, not only by their own preferences, but in relation to exclusionary and power-laden practices of colonial, now postcolonial, Australian state and society with respect to Indigenous people who continue to be seen as 'different'. But even oppressive change cannot be understood only deterministically: it develops along paths people take within circumstances as they encounter them. Not all change is simply repressive, nor is well-intentioned remedial change always liberatory. Most importantly, as Joel Robbins points out, we have not adequately developed critical categories needed to characterise change and people's perception of it. Many social science theorisations of change take it that the 'new' is always perceived through the 'old', but this leaves unexplored cultural constructs of novelty, the very question of what people perceive as new, and how.

I have grouped Tonkinson and Morphy together in that they start/ed from another end of a spectrum: from assumptions that there are certain domains or areas of social practice that are central and relatively impervious to change. While Indigenous Australians no doubt see supreme value in some kinds of activity - like ritual - over others, this does not by itself tell us how they may act to preserve it, or not do so. We also need to be able to account for those reports, and experiences, of Indigenous people who decide that rituals should not be reproduced, that sacra should be given away or given into custody, sold (Batty 2006). Any such explanations must take account of changes in Indigenous people's relations among themselves, and between themselves and outsiders. Recent work by Tonkinson moves much more, as he himself notes, to foreground 'Western impacts', but still requires a conceptual basis for dealing with these observations. In any case it is clear that we cannot, in this field as in others, unproblematically attribute continuity to Indigenous practice and experience without considering the question of repositioning of practices and values posed by Indigenous-non-Indigenous co-presence, mutual awareness, and forms of interaction. 
Are changes in kinship and certain kinds of social relations more or less open to change? There often seems to be a supposition that domestic, familial and kin relations are more persistent and less permeable (as the Morphys posit of the Yolngu). Yet there is still a dearth of solid suggestions and evidence about how to critically evaluate what is persistent, and what more fluid, in these relations that clearly, in many places, remain observably different from other patterns.

It is, I have suggested, not fortuitous that Tonkinson's and Morphy's domainlinked claims of centrality have emerged from research grounded in religion, ritual, and art. These, as recent developments have shown, are indeed constituted within Indigenous practice and value as special, high cultural, frames if you will. In fact, much of what we now call Aboriginal 'art' was originally not detachable from the framework of ritual. But I have suggested that in some ways high valuation, in historically particular contexts, has made some of these practices readily transposable into new, constructed frames (of art galleries, museums, performance spaces), where indeed the high valuation that Indigenous people have long attributed to them can be renewed and reshaped-in interaction, often, with outsiders.

In other historically particular settings such as that of the Wiradjuri, comparable practices have waned, and disappeared, and undoubtedly in earlier times were sometimes discouraged or overtly suppressed. The range of newly constructed frames, like the art market and Garma, selectively reach well outside the Yolngu social space to connect particular people with institutions and markets elsewhere. No similar sort of cultural product has emerged from within the interrelation of Wiradjuri and non-Indigenous Australia. In these spatial, material and social shifts of Yolngu art there are dimensions of both continuity and change. This invites further consideration (see Anderson 1995, for instance) of what methodological and theoretical tacks we may take in trying to analyse what happens when something that was formerly Indigenous-internal is brought to an external audience - rather than simply assuming, or idealising, its continuity.

\section{References}

Anderson, C (ed.) (1995) Politics of the secret. Oceania Monographs, Sydney.

Austin-Broos, D (2011) A different inequality: the politics of debate about remote Aboriginal Australia. Allen and Unwin, Sydney.

Baker, G (2010) 'We just cry for our country': the boycott and the Goulburn Islanders. Australian Historical Studies 41(3): 302-18. 
Batty, P (2006) White redemption rituals: reflections on the repatriation of Aboriginal secret-sacred objects. In T Lea, E Kowal and G Cowlishaw (eds) Moving anthropology: critical Indigenous studies. Charles Darwin University Press, Darwin: 55-63.

Hacking, I (1999) The social construction of what? Harvard University Press, Cambridge, Mass.

Hart, K (2002) Anthropologists and development. Norsk Antropologisk Tidsskrift 13(1-2): 14-21.

Macdonald, G (2004) Two steps forward, three steps back: a Wiradjuri land rights journey. LhR Press, Canada Bay.

Macdonald, G (2008) Difference or disappearance: the politics of Indigenous inclusion in the liberal state. Anthropologica 50(2): 341-58.

Merlan, F (1998) Caging the rainbow: places, politics and Aborigines in a north Australian town. University of Hawai'i Press, Honolulu.

Merlan, F (2001) From cultural production to Aboriginal art. In Thomas, $\mathrm{N}$ and Pinney, C (eds) Beyond aesthetics. Berg, London: 201-34.

Morphy, H (1991) Ancestral connections: art and an Aboriginal system of knowledge. University of Chicago Press, Chicago.

Morphy, F and Morphy, H (2013) The hegemony of the 'mainstream': anthropological theory and government policy in Australia's Northern Territory. American Anthropologist 115(2): 174-87.

Palmié, S (1995) Against syncretism: 'Africanizing' and 'Cubanizing' discourses in North American òrìsà worship. In R Fardon (ed.) Counterworks: managing the diversity of knowledge. Routledge, London: 73-104.

Petri, H and Petri-Odermann, G (1970) Stability and change: present-day historic aspects among Australian Aborigines. In RM Berndt (ed.) Australian Aboriginal anthropology. University of Western Australia, Perth: 248-76.

Robbins, J (2007) Continuity thinking and the problem of Christian culture: belief, time and the anthropology of Christianity. Current Anthropology 48(1): 5-38.

Sharp, L (1952) Steel axes for Stone-Age Australians. Human Organization 11(2): 17-22. 
Tonkinson, R (1970) Aboriginal dream-spirit beliefs in a contact situation: Jigalong, Western Australia. In R Berndt (ed.) Australian Aboriginal anthropology. University of Western Australia, Perth: 277-91.

Tonkinson, R (1974) The Jigalong mob: Aboriginal victors of the desert crusade. Cummings, Menlo Park.

Tonkinson, R (2004) Spiritual prescription, social reality: reflections on religious dynamism. Anthropological Forum 14(2): 183-201.

Tonkinson, R (2007) Aboriginal 'difference' and 'autonomy' then and now: four decades of change in a Western Desert society. Anthropological Forum 17(1): 41-60.

Tonkinson, R (2012) Anthropologies of change: theoretical and methodological challenges. In P McGrath and T Bauman (eds) Anthropological approaches to the study of social change. a workshop for native title anthropologists. AIATSIS, Canberra: 18-23.

Tonkinson, R and Tonkinson, M (2010) The cultural dynamics of adaptation in remote Aboriginal communities: policy, values and the state's unmet expectations. Anthropologica 52(1): 67-75. 
This text is taken from Change! Combining Analytic Approaches with Street Wisdom, edited by Gabriele Bammer, published 2015 by ANU Press, The Australian National University, Canberra, Australia. 